\section{HFEA responds on germline therapy}

As chief executive of the UK Human Fertilisation and Embryology Authority (HFEA), I take issue with Marcy Darnovsky's criticisms of our public consultation on mitochondria replacement in reproductive therapy (Nature 499, 127; 2013).

Darnovsky queries the statistic used by the HFEA: "one in 200 children is born each year with a form of mitochondrial disease." This comes from a study of mitochondrial mutations in the general population (H. R. Elliot et al. Am. J. Hum. Genet. 83, 254$260 ; 2008)$ and includes children with mild or no symptoms. Other UK organizations use the same figure, notably the National Health Service (see go.nature. com/dcocm2) and the Nuffield Council on Bioethics (see go.nature.com/s6z8gk) .

Darnovsky also questions parts of the HFEA's methodology and conclusions. The consultation was designed with external experts, and enabled public participation in various 'strands' that used qualitative and quantitative analysis. Our aim was to go beyond 'yes' or 'no' responses. In all but one of five strands, most people supported mitochondriareplacement techniques. Our publicly open questionnaire drew more opposition from its self-selected respondents, with some arguing that any in vitro manipulation of embryos is inappropriate or unethical.

All the consultation material is available at our website (www. hfea.gov.uk/7784.html). I suggest that people judge for themselves. Peter Thompson HFEA, London. peter.thompson@hfea.gov.uk

\section{Ireland's research output set to slide}

In the first global Nature Publishing Index (see go.nature. $\mathrm{com} / \mathrm{vbqdbr}$ ), Ireland is ranked 20th in the Global Top 100 for
2012 and is identified as one of five countries to watch, on the basis of a marked increase in the number of its publications in Nature Publishing Group research journals. Watchers could be disappointed when the next index is released.

Ireland's research output is under threat. Research career frameworks are being formulated and implemented by several major Irish universities. These effectively limit researchers' careers to six years through the enforcement of an 'up or out' policy, whereby they must either secure increased funding to rise through the ranks, or leave the university.

There is now a real risk that Ireland's talented researchers will be forced out as they reach the end of their allotted research time. They are left with the choice of going into industry, moving abroad to continue their research, or dropping out of science.

Mark Jessopp, Ruairi O'Reilly, Gordon Dalton University College Cork, Ireland. m.jessopp@ucc.ie

\section{New electricity grids must develop in sync}

Future US and European electricity systems will depend on the harmonious evolution of low- and medium-voltage 'smart' grids with high-voltage 'super' grids (see M. Amin Nature 499, 145-147; 2013). Without care, these two developments could undermine, rather than reinforce, one another.

Both smart and super grids involve three layers (see go.nature. com/7flk7s): physical (power flows), cyber (information technology) and socio-economic (stakeholders). There are important issues in the physical layer, but the greatest tensions will emerge in the socioeconomic layer as self-interested stakeholders advance local or continental interests.

Smart grids relate to local consumers becoming electricity producers themselves. This could diminish the need for highvoltage transmission grids as local power starts to serve nearby users.

Super grids will help to integrate massive renewable sources and to ensure reliability. Their development will be led by transmission companies at a time when those businesses must adapt to emerging smart grids.

If smart and super approaches are not aligned, the result will be a frailer electricity system. It is not just technologies that need to match up: policy regulations and market structures must do so too.

Smartness should not just be an issue for better local grids, but for the electricity system as a whole.

Ettore Bompard, Marcelo

Masera European Commission Joint Research Centre, Institute for Energy and Transport, Petten, the Netherlands.

William J. Nuttall The Open University, Milton Keynes, UK. william.nuttall@open.ac.uk

\section{Curb clearance for oil-palm plantations}

We question whether using accurate genotyping to enhance palm-oil yields will greatly reduce the acreage devoted to palm-oil plantations (R. Singh et al. Nature http://doi.org/ndc; 2013).

Global demand for palm oil by the food industry and for biofuel is rising, pushing expansion of plantations into forests and peatlands. As higher yields generate bigger profits, more companies will venture into palm-oil production and marginal lands may be developed.

Moves to increase palmoil yields should therefore be combined with strict government controls on the expansion of existing plantations into environmentally sensitive areas.

Some countries have imposed restrictions on new plantation licences, but with limited success. In Indonesia, for example, the recent severe widespread smoke haze was mainly associated with peatland clearance for oil palms, and almost half of these fires occurred in areas with a moratorium for new licences (see go.nature.com/doiwwf). Finn Danielsen Nordic Agency for Development and Ecology, Copenhagen, Denmark. fd@nordeco.dk

Faizal Parish Global Environment Centre, Selangor, Malaysia.

\section{Seize diplomats smuggling ivory}

One route for the smuggling of wildlife parts, such as rhino horn and elephant ivory, could be closed without the need for new international conventions or treaties (B. I. Kaaria and N. L. Muchiri Proc. 9th Int. Conf. Environ. Compliance Enforc. 204-208; 2011). Rogue diplomats must be stopped from exploiting their consular immunity to flout customs regulations and support this illicit trade.

The scale of the problem is unquantifiable, but anecdotal evidence indicates that it is widespread. Diplomatic bags containing horn were reported to be evading customs checks as long ago as the 1980s (E. B. Martin Pachyderm 21, 28-34; 1996). In 2011, a South Korean diplomat was caught smuggling ivory (see go.nature.com/fuo43s).

Countries could adopt the UK practice of giving full immunity only to diplomats who are accredited to that country; others who pass through British territory are subject to regular checks. Because there are few direct flights between African and Asian capitals, diplomats would run the risk of also being checked at European airports when changing flights.

Apprehending diplomats carrying illegal materials would generate negative publicity, forcing countries to punish errant civil servants and reduce the problem. Immunity should not mean impunity.

Kelvin S.-H. Peh University of Southampton, UK. kelvin.peh@gmail.com 